\title{
Quiste esplénico congénito complicado en un niño
}

\section{Complicated congenital splenic cyst in a child}

\author{
Patricia Flores-Pérez, ${ }^{1}$ María José Hernández-Rodríguez, ${ }^{1}$ Ana Lourdes Luis-Huertas, ${ }^{2}$ Gustavo Albi-Rodríguez ${ }^{3}$
}

\section{Resumen}

INTRODUCCIÓN: Los quistes esplénicos aislados son raros en niños y potencialmente graves y casi siempre difíciles de diagnosticar.

CASO CLínICO: Paciente de 5 años, traído a urgencias por fiebre alta, dolor abdominal y vómito. Reporte hematológico: leucocitosis con elevación de reactantes de fase aguda, hemocultivo negativo y coprocultivo positivo para Salmonella serogrupo D. En la radiografía de tórax se objetivó infiltrado basal izquierdo y derrame pleural; en la ecografía abdominal se detectó lesión quística intraesplénica de gran tamaño. Con el diagnóstico de absceso gigante del bazo se pautó tratamiento antibiótico intravenoso y drenajes percutáneos repetidos hasta la intervención quirúrgica definitiva con extirpación quística parcial y fenestración de la cápsula. En el cultivo del absceso creció una Salmonella del mismo serogrupo. El análisis anatomopatológico de la pieza fue compatible con quiste epitelial primario.

CONCLUSIONES: Como parte del diagnóstico diferencial de cualquier paciente con signos sugerentes de afectación en el hipocondrio izquierdo deben considerarse los quistes esplénicos. En los últimos años ha habido grandes avances en su tratamiento; en pacientes pediátricos suele ser conservador.

PALABRAS CLAVE: Quiste epitelial; absceso esplénico; esplenectomía; niños

\section{Abstract}

INTRODUCTION: Isolated splenic cysts are rare in children, potentially life-threatening, and often difficult to diagnose. We introduce a complicated case with bacterial superinfection and abscessing, to facilitate recognition and early diagnostics, and discuss about best treatment options.

CASE REPORT: 5-year-old boy brought to the ER by high fever, abdominal pain and vomiting. In the blood test showed leukocytosis with elevated acute phase reactants, negative blood culture and positive stool culture for Salmonella serogroup D. In the chest radiograph was observed a left basal infiltrated with pleural effusion, and in the abdominal ultrasound, a large cystic intrasplenic lesion. With the diagnosis of giant splenic abscess, intravenous antibiotic treatment and repeated percutaneous drainage were established until the definitive surgery with cystic partial removal and capsule fenestration. In the culture of the abscess it grew a Salmonella of the same serogroup. Histopathological examination of the specimen was consistent with primary epithelial cyst. CONCLUSIONS: Splenic cysts should be considered in the differential diagnosis of any patient with signs suggestive of pathology in the left upper quadrant. In recent years there has been great progress in its handling that in the case of children it is usually conservative.

KEY WORDS: Epithelial cyst; splenic abscess; Splenectomy; Children
${ }^{1}$ Médico especialista en pediatría y sus áreas específicas, facultativo especialista adjunto al servicio de Pediatría, sección hospitalización.

${ }^{2}$ Médico especialista en cirugía infantil, facultativo especialista adjunto al servicio de Cirugía general.

${ }^{3}$ Médico especialista en Radiodiagnóstico, facultativo especialista adjunto al servicio de Radiodiagnóstico.

Hospital Infantil Universitario Niño Jesús, Madrid, España.

Recibido: 11 de agosto 2016

Aceptado: 21 de noviembre 2017

\section{Correspondencia}

Patricia Flores Pérez

pfloresperez@gmail.com

Este artículo debe citarse como Flores-Pérez $P$, Hernández-Rodríguez MJ, Luis-Huertas AL, Albi-Rodríguez G. Quiste esplénico congénito complicado en un niño. Acta Pediatr Mex. 2018;39(4):316-322. 


\section{INTRODUCCIÓN}

Los quistes esplénicos son relativamente raros, pues su incidencia es menor de $0.07 \%{ }^{1}$ sin embargo, últimamente se ha incrementado con la aplicación, cada vez más extendida, de técnicas de imagen más sensibles en el estudio de la patología abdominal. A pesar de la existencia de éstas su diagnóstico y tratamiento siguen siendo un reto difícil para muchos médicos y cirujanos debido, en parte, a la falta de guías precisas de actuación.

La mayor parte de los casos reportados son de adultos como consecuencia de una enfermedad parasitaria adquirida. Los quistes congénitos más frecuentes en niños suelen ser únicos, benignos y asintomáticos. La mayor parte de las veces son un hallazgo durante una exploración física o ecográfica. Muy rara vez se complican con peritonitis, hemorragia, ruptura, compresión renal, hipertensión o carcinoma, en cuyo caso el pronóstico puede ser funesto.

El tratamiento de los quistes no parasitarios ha cambiado en las últimas dos décadas con el reconocimiento de la importante función inmunológica del bazo, sobre todo en los menores de 5 años, y con los avances tecnológicos en cirugía, que permiten un enfoque más conservador por laparoscopia o cirugía abierta. Aun así, no todos los quistes pueden resecarse por cistectomía o esplenectomía parcial.

El objetivo de este trabajo fue: reportar el caso de un paciente de edad inferior a la media publicada, tratado en nuestro servicio, con un absceso esplénico gigante que afectó la función pulmonar por la diseminación hematógena y siembra bacteriana sobre un quiste epitelial primario preexistente; se trató conservadoramente, con éxito, mediante esplenectomía parcial. Asimismo, revisar la bibliografía del tema para aumentar la conciencia de este padecimiento excepcional en pacientes pediátricos.

\section{CASO CLÍNICO}

Paciente masculino de 5 años, Ilevado a Urgencias debido a la coexistencia de fiebre alta de 4 días de evolución, dolor abdominal periumbilical, vómito y erupción cutánea evanescente en el tronco. Como antecedente destacó su ingreso a otro hospital 15 días antes por gastroenteritis por Salmonella spp y dos episodios posteriores, a los 5 y 10 días desde el alta, de fiebre y dolor abdominal. Durante la exploración se le encontró febril, taquipnéico, con signos de dificultad respiratoria, hipoventilación en la base pulmonar izquierda y dolor a la palpación en el hipocondrio izquierdo.

El análisis de sangre reportó leucocitosis con desviación izquierda, proteína $C$ reactiva 285 $\mathrm{mg} / \mathrm{dL}$, procalcitonina $5,63 \mu \mathrm{g} / \mathrm{mL}$, hemocultivo negativo y coprocultivo positivo para Salmonella serogrupo D. En la radiografía de tórax se objetivó infiltrado basal izquierdo y derrame pleural, que se drenó en UCIP y se obtuvo un líquido pleural con características de exudado y cultivo negativo.

Con el diagnóstico de neumonía basal izquierda se decidió hospitalizarlo para tratamiento antibiótico intravenoso con ampicilina $(150 \mathrm{mg} / \mathrm{kg} /$ día) y administración de oxígeno. Al tercer día, por persistencia de los síntomas, se solicitó una ecografía abdominal en la que se observó una lesión quística intraesplénica de gran tamaño (aproximadamente $113 \times 103 \times 116 \mathrm{~mm}$ ), hipoecogénica y homogénea (Figura 1). Se realizó una punción-aspiración guiada y se dejó un catéter tipo pigtail en el interior (Figura 2), con mejoría clínica y analítica inmediata.

En el cultivo del absceso creció Salmonella serogrupo D. El drenaje permaneció durante 10 días; los datos clínicos reaparecieron a los 5 días del retiro del catéter, con un nuevo pico febril y aumento de las necesidades de oxígeno 


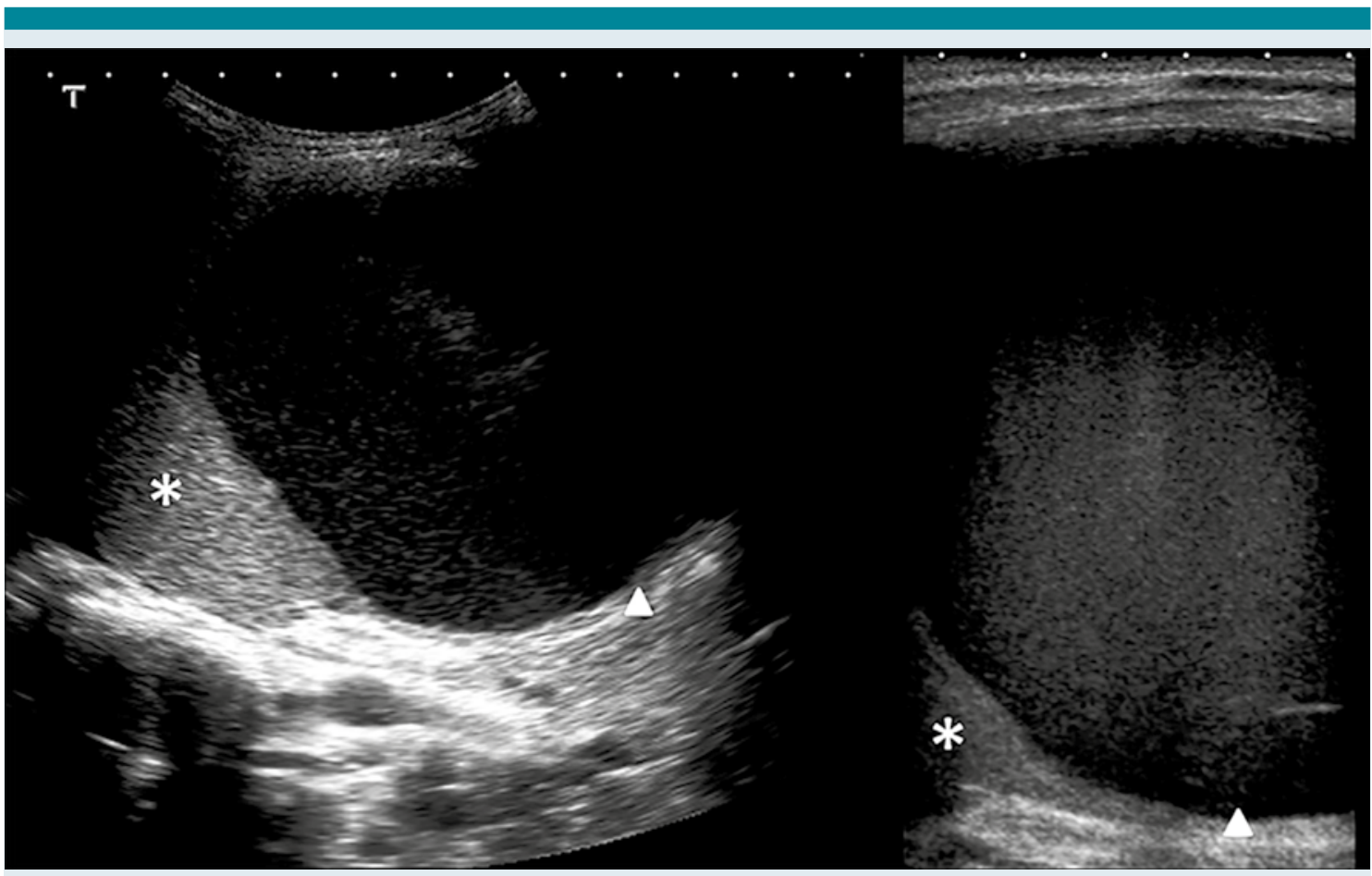

Figura 1. Ecografía intresplénica que muestra una gran lesión quística (punta de flecha) en el interior del bazo (asterisco).

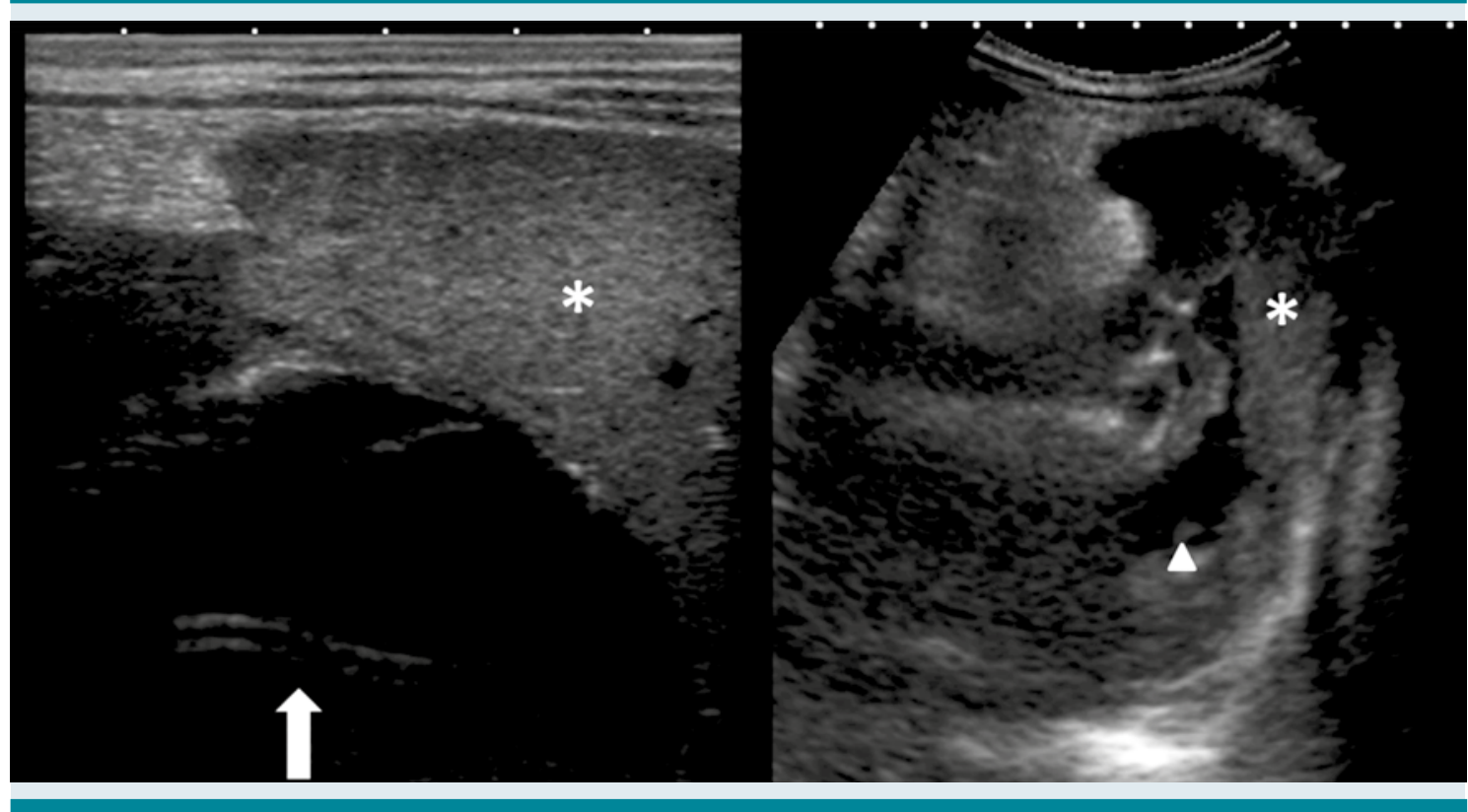

Figura 2. Ecografía tras punción-aspiración con drenaje tipo pigtail. Catéter tipo "pigtail" (flecha) en el interior del quiste esplénico que se identifica colapsado (punta de flecha) en la imagen de control. Bazo (asterisco). 
suplementario. Ante la confirmación ecográfica del aumento del tamaño de la colección líquida intraesplénica y hepatización del lóbulo inferior izquierdo pulmonar, se decidió una tomografía computada (Figura 3) para definir la localización exacta de la lesión y su relación con las estructuras vecinas. Se volvió a drenar guiándose con control ecográfico y se programó para capsulectomía definitiva. En la intervención se encontraron una lesión grande encapsulada en la región anterior del bazo, en relación directa con el ligamento gastrocólico y la cúpula vesical, de contenido mixto purulento-sanguinolento. Se efectuaron la extirpación quística parcial y la fenestración de la cápsula. El análisis anato-

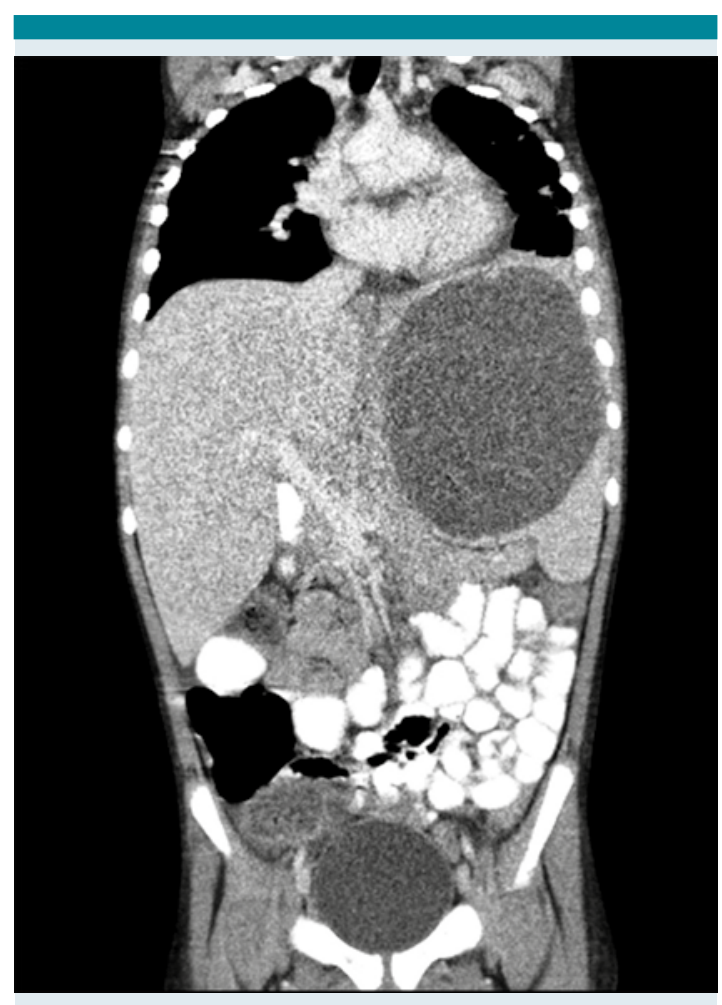

Figura 3. Tomografía computada del quiste esplénico gigante en el que se ha formado un absceso y se observa una lesión quística intraesplénica de gran tamaño, hipodensa, homogénea, sin tabiques. Provoca efecto de masa con elevación del hemidiafragma, compresión del estómago y del riñón izquierdo y desplazamiento caudal de los vasos esplénicos. mopatológico de la pieza fue compatible con quiste epitelial primario.

Al cabo de seis semanas de tratamiento con una cefalosporina de tercera generación la evolución clínica se consideró satisfactoria. Permaneció asintomático en las revisiones posteriores, aunque en las radiografías de tórax de control a los seis meses aún persistían los tractos fibrosos residuales y la pérdida de volumen a nivel basal izquierdo. La espirometría basal reportó afectación restrictiva de la función pulmonar con $\mathrm{FEF} 25-75 \%$ 56\%, con requerimiento de fisioterapia respiratoria.

\section{DISCUSIÓN}

Este paciente tuvo un absceso gigante esplénico e infección por Salmonella entérica quizá favorecida por un quiste esplénico preexistente.

En la arquitectura esplénica, los quistes son, en general, poco frecuentes y suelen permanecer asintomáticos mucho tiempo o tener manifestaciones vagas, a no ser que se compliquen (infección, ruptura, hipertensión, sangrado o degeneración maligna). Como resultado del uso extendido del diagnóstico por imagen, los datos acerca de su incidencia están aumentando en todo el mundo. La edad al diagnóstico en niños alcanza su máximo entre los 10-13 años, con diámetro variable de 1 a $20 \mathrm{~cm}$ (se consideran "gigantes" cuando son mayores de $15 \mathrm{~cm}$ ) y suelen localizarse en el polo superior del bazo. ${ }^{2}$ Afectan con más frecuencia a los varones con una relación de $2: 1 .^{3}$

Estos quistes se dividen de acuerdo con la clasificación de Fowler, modificada más tarde por Martin ${ }^{4}$ en primarios o verdaderos $(10 \%)$, con un revestimiento interno endotelial y en pseudoquistes secundarios a un traumatismo, infección o infarto. Los primeros se subdividen en parasitarios o hidátides por Echinococcus 
species, y no parasitarios o congénitos, que representan $2.5 \%$ de todos los quistes esplénicos diagnosticados en la infancia ${ }^{5}$ y cuya patogénesis es aún conjetural, proponiéndose la inclusión de células embrionarias epiteliales desde tejido extraesplénico adyacente.

La mayor parte de los síntomas se relacionan con el tamaño del quiste; los más pequeños, normalmente, son asintomáticos hasta que alcanzan, al menos, $6 \mathrm{~cm}$ de diámetro. ${ }^{6}$ Los pacientes suelen referir molestias en el cuadrante superior izquierdo acompañadas de otros síntomas debidos a la compresión de órganos adyacentes, como: sensación de plenitud, náuseas, vómito, flatulencia o diarrea. ${ }^{7}$ La exploración física revela, en la mitad de los casos, esplenomegalia o una masa palpable, más o menos dolorosa, en el mismo flanco.

Aún no se dispone de una prueba específica de laboratorio pero hace poco se descubrió que el contenido quístico puede ser positivo para el marcador tumoral Ca 19-9, que pasa a la circulación sistémica, aun sin potencial maligno. ${ }^{7}$ Cuando los quistes se sobreinfectan, como en nuestro caso, aparece fiebre, leucocitosis y dolor abdominal intenso que, en ocasiones, puede referirse hacia el hombro ipsilateral o la parrilla costal por afectación diafragmática o derrame pleural asociado. ${ }^{8}$ Sin embargo, son raros los niños que aquejan, desde el principio, como el nuestro, síntomas respiratorios e insuficiencia pulmonar, por implicación directa del parénquima.

En los cultivos del absceso, positivos incluso en $74 \%$ de los casos, ${ }^{9}$ pueden crecer distintas especies bacterianas, casi todas procedentes de la flora intestinal. Los inducidos por Salmonella, como el aquí comunicado, son, desde la llegada de los antibióticos, una complicación extraintestinal muy rara de la fiebre no tifoidea. Por lo general existen condiciones predisponentes, como la anemia de células falciformes o algún estado de inmunosupresión. ${ }^{10}$ En nuestro caso, asumimos que el quiste congénito asintomático subyacente actuó como factor precipitante para la formación del absceso luego de una siembra bacteriana por vía hematógena durante una bacteriemia transitoria.

En el diagnóstico de los quistes esplénicos, complicados o no, los mayores avances se han conseguido en radiología y medicina nuclear; la ecografía y la tomografía computada son las pruebas diagnósticas de elección, con una sensibilidad superior a 90\%. ${ }^{11}$ Ambas técnicas permiten caracterizar la lesión (componente hemorrágico, tejido graso, etc.) y estudiar su tamaño y relación con las estructuras adyacentes, información muy útil en el diagnóstico diferencial y tratamiento. La ecografía también es útil para guiar los procedimientos de aspiración del quiste y en el seguimiento conservador de la enfermedad. La tomografía computada, según gran parte de los protocolos, es útil antes de cualquier procedimiento quirúrgico para indicar el mejor sitio de acceso e inferir si es posible la esplenectomía parcial. ${ }^{12}$

La aproximación terapéutica actual de los quistes esplénicos no parasitarios está dictada por la existencia o no de síntomas y el tamaño del quiste, sin que haya directrices claras basadas en la evidencia debido a su baja incidencia. Las recomendaciones se fundamentan, más bien, en estudios pequeños con niños y adultos. Así, desde la publicación en 1992 del trabajo de Musy y su grupo ${ }^{11}$ de ocho pacientes pediátricos con quistes esplénicos, se toma como punto de corte $5 \mathrm{~cm}$ para decidir entre actitud expectante o intervención. Los quistes menores de $5 \mathrm{~cm}$ suelen desaparecer espontáneamente y podría hacerse un seguimiento seriado. Cuando las lesiones son mayores, en general se acepta que deben drenarse o resecarse para evitar su ruptura, sangrado o degeneración, tanto si el paciente 
está sintomático o no. Sin embargo, un estudio más reciente, retrospectivo, ${ }^{13}$ pone en duda la validez de este punto de corte y considera más acertado observar a todos los pacientes asintomáticos con imágenes seriadas para evaluar la tasa de crecimiento y detectar los síntomas.

Por lo que se refiere a la técnica quirúrgica, el acceso clásico era la esplenectomía total abierta hasta que, el reconocimiento de la importante función inmunológica del bazo, con riesgo de complicaciones graves a medio y largo plazo (riesgo de sepsis posesplenectomía del $4 \%$ y tasa de mortalidad del $1,5 \%),{ }_{1}^{14}$ hizo que, siempre que sea posible, el tratamiento en la edad pediátrica sea conservador. ${ }^{15}$ Los objetivos son: retirar el quiste entero, preservar el tejido esplénico y evitar las recurrencias. Las opciones quirúrgicas se basan en el tamaño del quiste, su relación con los vasos del hilio y el parénquima, y la cantidad de tejido sano remanente; ${ }^{16}$ incluyen aspiración, escisión parcial o completa y esplenectomía parcial. ${ }^{17}$ La esplenectomía total sólo está indicada en los quistes gigantes, complicados o no, que ocupan prácticamente todo el parénquima y que abarcan el hilio. ${ }^{1}$ El riesgo intraoperatorio más grave es la ruptura esplénica durante el procedimiento y la hemorragia.

La aspiración percutánea guiada por ecografía, con colocación de catéter, junto con la cobertura antibiótica apropiada, es una técnica fiable con una alta tasa de éxito, sobre todo si el contenido es suficientemente líquido, sin septos ni restos necróticos. ${ }^{18}$ Este procedimiento es muy practicado como medida temporal en pacientes inestables o críticamente enfermos porque por lo general consigue que la recuperación sea rápida en la condición del paciente. ${ }^{19}$ El problema que plantea es la alta tasa de recurrencia, por persistencia del revestimiento epitelial, que disminuye al asociarse la escleroterapia. ${ }^{20}$ Además, puede producir adherencias con los órganos adyacentes y una densa respuesta inflamatoria alrededor del bazo. Con nuestro caso demostramos que, si el drenaje percutáneo es insuficiente para una curación total, se mantiene como primera etapa de intervención válida, aumentando las posibilidades de éxito de la cirugía, al disminuir el tamaño de la lesión y eliminar el contenido purulento.

La cistectomía parcial con fenestración de la pared capsular, descrita por primera vez en niños por van der Zee ${ }^{18}$ parece otra opción relativamente sencilla, aunque puede recurrir si no se coagula de forma precisa la superficie interna del remanente, por lo que algunos autores abogan directamente por la cistectomía total con o sin tejido esplénico. ${ }^{21}$

Por último, la esplenectomía parcial, descrita desde finales del siglo pasado, ${ }^{22}$ se ha vuelto segura y factible con el mejor conocimiento de la anatomía vascular del bazo, que permite su segmentación intraoperatoria para evitar grandes sangrados posquirúrgicos. ${ }^{23}$

Así, los recientes avances en las técnicas operatorias, la hemostasia con pegamento de fibrina, la ablación con radiofrecuencia y las nuevas técnicas de grapado han contribuido a facilitar la conservación del tejido esplénico y su función homeostática. ${ }^{15}$

\section{CONCLUSIONES}

Los quistes esplénicos verdaderos son lesiones raras, casi siempre únicas, pequeñas y esporádicas, por lo general benignas, aunque pueden ser potencialmente mortales por crecimiento, ruptura o infección secundaria, como en el caso aquí reportado. El tratamiento ideal sigue siendo incierto y casi todas las recomendaciones se basan, principalmente, en estudios pequeños de adultos. Los trabajos más recientes coinciden en recalcar la importancia de esbozar estrategias terapéuticas que permitan la conservación del 
bazo y de individualizar los tratamientos según el paciente y su situación de base. Este caso y la revisión de la bibliografía sirven para aumentar la conciencia de este padecimiento excepcional.

\section{REFERENCIA}

1. Shukla RM, Mukhopathyay M, Mandal KC, Mukhopadhyay. Giant congenital infected splenic cyst: an interesting case report and review of the literature. Indian J Surg. 2010; 72:260-262.

2. Sinha CK, Agrawal M. Nonparasitic splenic cysts in children: Current status. Surgeon. 2011;9(1):49-53.

3. Meunier A, Closset J, Cassart M, Houben JJ, Lingier P. Management of congenital and posttraumatic splenic cysts in children. Hepatogastroenterology. 2008;55(81):286-8.

4. Martin JW. Congenital splenic cysts. Am J Surg. 1958; 96:302-8.

5. Panossian $D H$, Wang $N$, Reeves $C D$, Weeks DA. Epidermoid cyst of the spleen presenting as a generalized peritonitis. Am Surg.1990;56(5):295-8.

6. Garza-Serna U, Ovalle-Chao C, Martinez D, Flores-Villalba E, Díaz-Elizondo JA, Garza-Luna UJ. Laparoscopic partial splenectomy for congenital splenic cyst in a pediatric patient: Case report and review of literature. Int J Surg Case Rep. 2017; 33:44-47.

7. Kang SI, Jeon SY. Primary non-parasitic splenic cyst: a case report. Korean J Hepatobiliary Pancreat Surg. 2013;17(3):139-41.

8. Navarrete A, Orellana F, Castro M, Manríquez L, Ríos H. Quiste esplénico sobreinfectado en paciente inmunocompetente. Cir Esp. 2008;84(1):45-54.

9. De Greef E, Hoffman I, Topal B, Broers C, Miserez M. Partial laparoscopic splenectomy for splenic abscess because of Salmonella infection: a case report. J Pediatr Surg. 2008;43(5): E35-38.

10. Karia N, Lakhoo K. Complicated congenital splenic cyst: saved by a splenunculus. Afr J Paediatr Surg 2011; 8:98-100.
11. Musy PA, Roche B, Belli D, Bugmann P, Nussle D, Le Coultre C. Splenic cysts in pediatric patients- a report on 8 cases and review of the literature. Eur J Pediatr Surg. 1992; 2:137-140.

12. Pastore V, Bartoli F. A report of a giant epidermoid splenic cyst. Afr J Paediatr Surg.2014; 11:67-70.

13. Kenney CD1, Hoeger YE, Yetasook AK, Linn JG, Denham EW, Carbray J, Ujiki MB. Management of non-parasitic splenic cysts: does size really matter? J Gastrointest Surg. 2014;18(9):1658-63.

14. Kimber C, Spitz L, Drake D, Kiely E, Westaby S, Cozzi F, et al. Elective partial splenectomy in childhood. J Pediatr Surg 1998; 33:826-9.

15. Choudhury SR, Debnath PR, Jain P, Kushwaha AS, Puri A, Chadha $\mathrm{R}$, et al. Conservative management of isolated splenic abscess in children. J Pediatr Surg. 2010; 45(2):372-5.

16. Thorne MT, Chwals WJ. Treatment of complicated congenital splenic cysts. J Pediatr Surg.1993;28(12):1635-6.

17. Fan H, Zhang D, Zhao X, Pan F, Jin ZK. Laparoscopic partial splenectomy for large splenic epidermoid cyst. Chin Med J (Engl). 2011;124(11):1751-3.

18. Van der Zee DC, Kramer WL, Ure BM, Mokhaberi B, Bax NM. Laparoscopic management of a large postraumatic splenic cyst in a child. Surg Endosc.1999; 13:1241-1242.

19. Ferraioli G, Brunetti E, Gulizia R, Mariani G, Marone P, Filice C. Management of splenic abscess: report on 16 cases from a single center. Int J Infect Dis. 2009; 13:524-30.

20. Rifai K, Berger D, Potthoff A, Manns MP, Gebel MJ. Fine needle sclerotherapy as a new effective therapeutic approach for nonparasitic splenic cysts: a case series. Dig Liver Dis. 2013;45(7):595-9.

21. Czauderna $P$, Vajda $P$, Schaarschmidt $K$, Kalman A, Jainsch $M$, Engelis A, Lewicki K, Verebely T, Koltai J, Petersons A, Pintér AB. Nonparasitic splenic cysts in children: a multicentric study. Eur J Pediatr Surg. 2006;16(6):415-9.

22. Morgenstern L, Shapiro SJ. Partial splenectomy for nonparasitic splenic cysts. Am J Surg.1980; 139:278-81.

23. Brown MF1, Ross AJ 3rd, Bishop HC, Schnaufer L, Ziegler MM, Holcomb GW 3rd. Partial splenectomy: the preferred alternative for the treatment of splenic cysts. J Pediatr Surg.1989; 24(7):694-6. 